\title{
Moisture Sorption Thermodynamic Properties of Corn Stover Fractions
}

\author{
C. Igathinathane, A. R. Womac, S. Sokhansanj, L. O. Pordesimo
}

\begin{abstract}
Efficient processing, handling, and storage of corn stover, a major crop-based biomass, require an understanding of the moisture sorption thermodynamic properties of its fractions. Moisture sorption thermodynamic properties of the major corn stover fractions such as leaf, stalk skin, and stalk pith were determined, utilizing the static gravimetric sorption isotherms data in the temperature range of $10^{\circ} \mathrm{C}$ to $40^{\circ} \mathrm{C}$. Brunauer-Emmet-Teller (BET) monolayer moistures of stover fractions, determined using standard and modified BET equations, decreased with an increase in temperature. Mean values of monolayer moisture contents were in the range from $3.8 \%$ to $4.9 \%$ d.b., and the whole range of associated water activity based on BET equations varied between 0.013 and 0.225. Net isosteric heat of sorption, evaluated using the Clausius-Claperon equation, and differential entropy values of stover fractions decreased exponentially with increased moisture and approached the latent heat of vaporization of pure water at around $20 \%$ d.b. The moisture sorption process was determined as enthalpy driven. Inequality in isokinetic and harmonic mean temperatures confirmed the enthalpy-entropy compensation theory. Among stover fractions, leaf had the greatest spreading pressure, followed by stalk skin and stalk pith. Spreading pressures increased with increase in water activity and decreased with temperature increase. Net integral enthalpy increased to a maximum and then decreased with increasing moisture content, whereas net integral entropy displayed an opposite trend. Mean values of the net integral enthalpy and entropy of stalk pith were the highest and progressively decreased for leaf and stalk skin.
\end{abstract}

Keywords. Corn, Enthalpy, Entropy, Isotherms, Stover, Thermodynamic, Water activity.

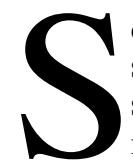
cience and technological developments are being supported to help establish biomass as a significant source of sustainable, environmentally sound, renewable feedstock for several bioenergy and bioproducts applications in the U.S. (USDOE, 2003). The U.S. Department of Energy plans the use of agricultural residue as a near-term source of biomass for renewable fuel, heat, power, chemicals and other biomaterials (Hoskinson et al., 2007). Among agricultural residues, corn stover (corn plant less grains, a major crop-based biomass) has the greatest potential as a biomass feedstock. Allowing for approximately $60 \%$ as ground cover for soil conservation practices, potential dry corn stover annual yields of about $204 \mathrm{Tg}$ globally, and about $132 \mathrm{Tg}$ in North America alone are available for utilization

Submitted for review in November 2006 as manuscript number FPE 6736; approved for publication by the Food \& Process Engineering Institute Division of ASABE in September 2007. Presented at the 2005 ASABE Annual Meeting as Paper No. 056047.

The authors are Cannayen Igathinathane, ASABE Member Engineer, Research Associate, Department of Agricultural and Biological Engineering, Mississippi State University, Mississippi State, Mississippi; Alvin R. Womac, ASABE Member Engineer, Professor, Department of Biosystems Engineering and Soil Science, The University of Tennessee, Knoxville, Tennessee; Shahab Sokhansanj, ASABE Member Engineer, Research Leader, Oak Ridge National Laboratory, Environmental Sciences Division, Oak Ridge, Tennessee; and Lester O. Pordesimo, ASABE Member Engineer, Assistant Professor, Department of Agricultural and Biological Engineering, Mississippi State University, Mississippi State, Mississippi. Corresponding author: Alvin R. Womac, Department of Biosystems Engineering and Soil Science, The University of Tennessee, 2506 E. J. Chapman Dr., Knoxville, TN 37996-4531; phone: 865-974-7104; fax: 865-974-4514; e-mail: awomac@utk.edu.
(Kim and Dale, 2004). Storage of harvested corn stover is an integral part of the supply chain in bioenergy and bioconversion practices. Understanding the thermodynamic properties of corn stover during storage aids in the development of efficient storage, processing, and handling systems.

Several researchers determined thermodynamic properties from moisture isotherms to provide information about moisture-solid site interaction, dehydration process energy requirements, sorption kinetic parameters, water properties, material microstructure, and physical phenomenon on material surface (Iglesias et al., 1976; Rizvi and Benado, 1984; Aviara and Ajibola, 2002; Kaya and Kahyaoglu, 2005). In the literature, the thermodynamic properties analyzed from the moisture sorption isotherms generally include monolayer moisture content, net isosteric heat of sorption, differential entropy, enthalpy-entropy compensation theory verification, spreading pressure, and net integral enthalpy and entropy.

Monolayer moisture is a limiting value below which the rate of quality loss is negligible (Bell and Labuza, 2000) and is determined using Brunauer-Emmet-Teller (BET) (Brunauer et al., 1938) or modified BET (Menkov, 2000) equations. The standard BET equation does not account for the temperature effect, but the modified BET equation incorporates the effect of temperature. Isosteric heat of sorption $\left(\mathrm{kJ} \mathrm{mol}^{-1}\right)$, defined as the heat of sorption at constant specific volume, evaluated using the Clausius-Claperon equation at constant moisture content, is a measure of moisture-solid site binding strength. Differential entropy $\left(\mathrm{kJ} \mathrm{mol}^{-1} \mathrm{~K}^{-1}\right)$ indicates the number of available moisture sorption sites at a specific energy level (Madamba et al., 1996). Heat of sorption and differential entropy values at specific moisture levels indicate the state of sorbed moisture, thereby providing a measure of 
physical, chemical, and microbiological stability of the material under specified storage conditions. The magnitude and variation of these values with moisture, relative to the latent heat of vaporization of pure water, provide insight into the moisture and solid site interaction, energy consumption, and design of drying equipment (McMinn and Magee, 2003).

Enthalpy-entropy compensation theory states that compensation occurs due to changes in solvent-solute interaction, and a linear relation exists between the enthalpy and entropy of the reaction (McMinn and Magee, 2003). Spreading pressure $\left(\mathrm{J} \mathrm{m}^{-2}\right)$, also known as surface potential, represents the surface excess free energy and indicates the increase in surface tension of bare sorption sites due to sorbed molecules (Fasina et al., 1999). Spreading pressure can be viewed as the force in the plane of the surface that must be exerted perpendicular to each unit length of edge to keep the surface from spreading (Smith et al., 2001). Net integral enthalpy $\left(\mathrm{kJ} \mathrm{mol}^{-1}\right)$, evaluated at constant spreading pressure, is also a measure of binding strength of moisture-solid system. Integral entropy $\left(\mathrm{kJ} \mathrm{mol}^{-1} \mathrm{~K}^{-1}\right)$ describes the degree of disorder or randomness of motion of the water molecules (Mazza and LeMaguer, 1978). Thermodynamic properties of agricultural materials have been reported earlier, for example melon and cassava (Aviara and Ajibola, 2002), potato (McMinn and Magee, 2003), soybean (Aviara et al., 2004), pestil (Kaya and Kahyaoglu, 2005), and tea (Arslan and Toğrul, 2006). These and other studies provide information on the various thermodynamic properties as discrete values or fitted models, obtained based on equilibrium moisture content, water activity, and temperature involved in the experimentation.

Among corn stover fractions, stalk (72.6\%) and leaf $(20.7 \%)$ dominate stover mass (Igathinathane et al., 2006). Stalk can be further divided into distinct stalk skin and stalk pith fractions. This division of stalk fractions is essential for moisture-solid site interaction analysis because, during crop harvest, the combine harvester subjects corn stalks to crushing, twisting, and pulling actions and exposes stalk pith to the environment for moisture exchange. Corn stover fractions stored at high humidity gain moisture, which promotes microbial activity leading to spoilage of biomass.

Published studies on equilibrium moisture relations of biomass materials are limited, although several studies have been reported on food materials. Literature on the thermodynamic properties of biomass is also scarce. Hence, there is a need to evaluate the thermodynamic properties of corn stover fractions. The objective of this study was to determine the thermodynamic properties, including monolayer moisture content, isosteric heat of sorption, differential entropy, spreading pressure, net integral enthalpy, and net integral entropy, for the selected corn stover fractions.

\section{Materials ANd Methods}

\section{SAMPLe Preparation}

Dekalb 743, a field corn variety, was the test material used for this study. Before the experiments, separated corn leaf and stalk sample stocks were stored at $-15^{\circ} \mathrm{C}$ in a laboratory freezer in airtight polyethylene bags. Corn leaves were cut into small pieces with scissors. Stalks are composed of thick fibrous skin that covers a core of spongy pith (fig. 1). The stalk skin and stalk pith were treated as separate materials in this analysis. Stalk skin and stalk pith samples were prepared

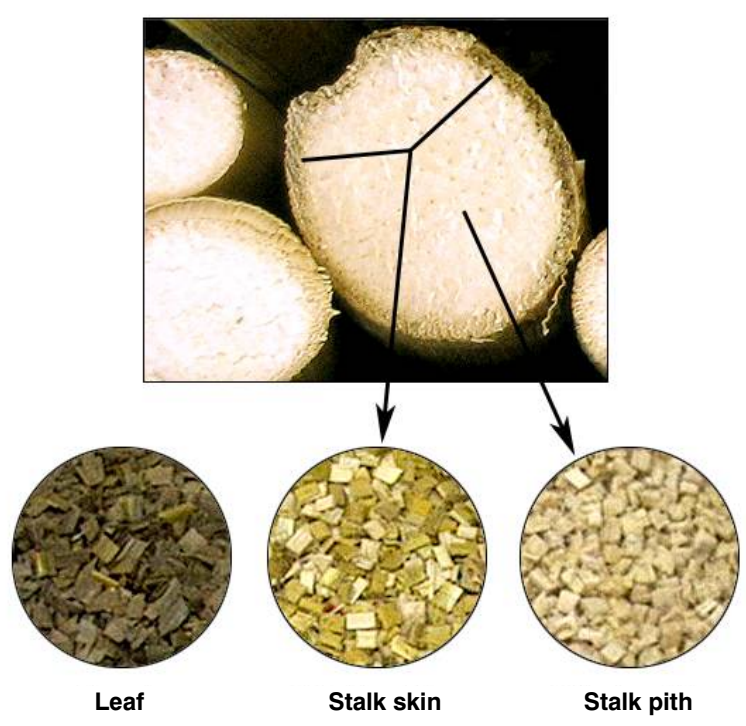

Figure 1. Sectioned corn stalk showing stalk skin and stalk pith, and prepared samples for sorption isotherm data collection.

from disk sections (depth $\approx 8 \mathrm{~mm}$ ) cut from stalks using a bandsaw with a fine blade. The disk sections of stalks were then manually separated into rings of stalk skin and disks of stalk pith. The stalk skin rings were manually broken into pieces, and the stalk pith disks were cut into six to eight sectors with a sharp knife. The prepared samples are also shown in figure 1. Measured initial moisture content (mean \pm standard deviation) was $8.11 \% \pm 0.68 \%$ dry basis (d.b.) for corn leaf, $12.19 \% \pm 1.98 \%$ d.b. for stalk skin, and $6.09 \% \pm 0.23 \%$ d.b. for stalk pith, based on the ASAE standard (ASAE Standards, 2003) moisture measurement procedure for forages.

\section{SORPTION ISOTHERM EXPERIMENT AND MODELED ISOTHERMS}

This study used a static gravimetric method that employed saturated salt solutions in glass desiccators (Igathinathane et al., 2005a) (fig. 2). Nine beakers (three replications each for corn leaf, stalk skin, and stalk pith) were held in each desiccator. Samples (6 to 10 pieces) having a total weight of approximately $0.2 \mathrm{~g}$ of corn leaf, $0.8 \mathrm{~g}$ of stalk skin, and $0.15 \mathrm{~g}$ of stalk pith were placed in each beaker. Desiccators loaded with samples and saturated salt solutions providing ten water activities ranging from 0.11 to 0.98 were then subjected to six temperature levels $\left(10^{\circ} \mathrm{C}, 20^{\circ} \mathrm{C}, 25^{\circ} \mathrm{C}, 30^{\circ} \mathrm{C}, 35^{\circ} \mathrm{C}\right.$, and $40^{\circ} \mathrm{C}$ ). Gross sample mass per beaker was recorded twice weekly with a digital balance $(0.0001 \mathrm{~g}$ resolution) for a total period of 26 days. Equilibrium moisture contents of samples were measured (ASAE Standards, 2003) when moisture equilibrium was reached based on constant mass $(\approx 0.001 \mathrm{~g} / 96 \mathrm{~h})$ between consecutive measurements. Detailed description of material and sample preparation is found elsewhere (Igathinathane et al., 2005b). Sorption isotherm data were collected at the six temperatures in combination with the ten water activities. The moisture sorption isotherm raw data thus obtained for corn stover leaf, stalk skin, and stalk pith reported earlier (Igathinathane et al., 2005b) were used to determine the various thermodynamic properties in this study.

Considering the equilibrium relative humidity as the water activity, the equilibrium moisture content (EMC) and water activity relationships of different corn stover fractions 


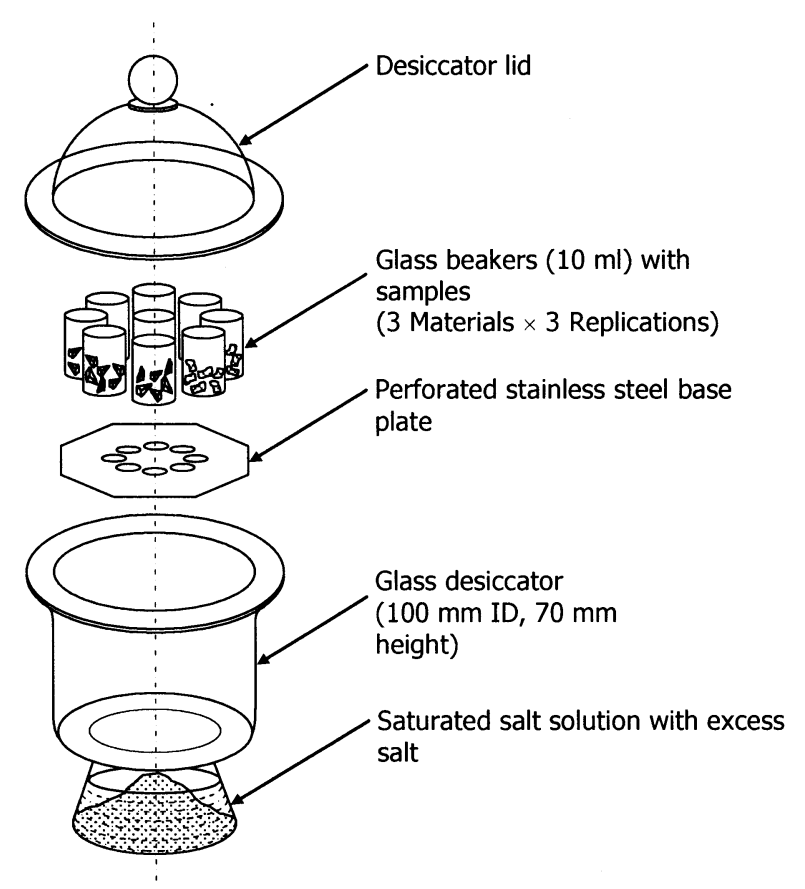

Figure 2. Static method of sorption isotherm data collection for corn stover fractions.

best described by the modified Oswin model are (Igathinathane et al., 2005b):

$$
\begin{aligned}
& \text { Leaf }: M=\left(12.8146-0.1167 T_{c}\right)\left[\frac{a_{w}}{1-a_{w}}\right]^{\frac{1}{2.5634}} \\
& \text { Stalk skin : } M=\left(10.8041-0.0580 T_{c}\right)\left[\frac{a_{w}}{1-a_{w}}\right]^{\frac{1}{2.7102}} \\
& \text { Stalk pith :M=(10.6099-0.0946T })\left[\frac{a_{w}}{1-a_{w}}\right]^{\frac{1}{1.9136}}
\end{aligned}
$$

where $M$ is the EMC (\% d.b.), $T_{c}$ is temperature $\left({ }^{\circ} \mathrm{C}\right)$, and $a_{w}$ is the water activity (decimal).

\section{Assumptions AND Limitations}

Cut sample particles were assumed to represent the original materials in their undisturbed state. The cutting operations in sample preparation could have disturbed cell tissues at cutting planes, but this effect was not considered. Growthsuppressing chemicals like phenyl mercury acetate or thymol were not included in the desiccators, to help study the natural microbial growth on samples during the moisture sorption experiments. Mold growth, observed only on samples subjected to increased water activities $\left(a_{w}>0.90\right)$, would have interfered with samples EMC values; however, this interference was assumed to be negligible. Results of the study were considered accurate in the studied temperature $\left(10^{\circ} \mathrm{C}\right.$ to $45^{\circ} \mathrm{C}$ ) and water activity $(0.11$ to 0.98$)$ range limits, but caution should be exercised when extrapolating results beyond these limits. In addition, a continuous and smooth variation of various results was assumed from the discrete data obtained at specified temperatures and water activities.

\section{Monolayer Moisture Content}

Monolayer moisture contents of stover fractions were obtained from the standard BET or modified BET equations. Menkov (2000) established a linear dependence between monolayer moisture content and temperature for a large number of biological products and proposed the modified BET equation incorporating temperature effect as:

$$
\begin{gathered}
M=\frac{\left(A+B T_{c}\right) C a_{w}}{\left(1-a_{w}\right)\left(1-a_{w}+C a_{w}\right)} \\
M_{m}=A+B T_{c}
\end{gathered}
$$

where $A, B$, and $C$ are model constants, and $M_{m}$ is the monolayer moisture content (\% d.b.). Equation 1 becomes the standard BET equation when the monolayer moisture content relationship (eq. 2) is considered directly as a single $M_{m}$ term. Since the standard BET equation does not involve the temperature effect, the monolayer moisture content should be calculated separately for each temperature.

Standard BET plots exhibiting a linear variation between $a_{w} /\left[M\left(1-a_{w}\right)\right]$ versus $a_{w}$ were used to determine the standard BET monolayer moisture content and constant $C$ (eq. 1) individually for each temperature at $a_{w}<0.45$. Non-linear regression using PROC NLIN of SAS (2002) evaluated the constants $(A, B$, and $C)$ of the modified BET equation (eq. 1) using the combined experimental data of all temperatures at $a_{w}<0.45$. Modified BET monolayer moisture values expressed as a function of temperature (eq. 2) were compared with the standard BET equation monolayer moisture values. The water activity value corresponding to the monolayer moisture content $\left(a_{w m}\right)$ was calculated from equation 1 by substituting $M=M_{m}$ (Iglesias and Chirife, 1976a; Menkov, 2000) as:

$$
a_{w m}=\frac{\sqrt{C}-1}{C-1}
$$

It can be seen from equation 3 that water activity corresponding to the monolayer moisture content is independent of temperature and is inversely proportional to the value of model constant $C$.

\section{NET IsOSTERIC HEAT OF SORPTION}

Net isosteric heat of sorption was determined using the Clausius-Claperon equation that relates water activity and temperature at a constant moisture content (Rizvi, 1986; Bell and Labuza, 2000):

$$
\left.\frac{\partial\left[\ln \left(a_{w}\right)\right]}{\partial[1 / T]}\right|_{M}=-\frac{q_{s t}}{R}
$$

where $T$ is the temperature $(\mathrm{K}), q_{s t}$ is the net isosteric heat of sorption $\left(\mathrm{kJ} \mathrm{mol}^{-1}\right)$, and $R$ is the universal gas constant $\left(8.31434 \times 10^{-3} \mathrm{~kJ} \mathrm{~mol}^{-1} \mathrm{~K}^{-1}\right)$.

This calculation procedure assumed that heat of sorption was independent of temperature change. The slope of the plot of $\ln \left(a_{w}\right)$ versus $1 / T$ at constant $M$ gave the net isosteric heat of sorption (eq. 4). Cubic spline interpolation determined the required $a_{w}$ values at specified moisture $(M)$ at various temperatures from the isotherm data. Adding latent heat of pure water to the net isosteric heat of sorption gave the isosteric heat of sorption $\left(Q_{s t}\right)$, which is also known as differential enthalpy. 


\section{DifFERENTIAL ENTROPY}

Substituting free Gibbs energy in the Gibbs-Helmholtz equation (McMinn and Magee, 2003; Kaya and Kahyaoglu, 2005), the differential entropy was calculated using the following equation:

$$
-\left.\ln \left(a_{w}\right)\right|_{M}=\frac{-\left(q_{s t}+\lambda\right)}{R T}-\frac{\Delta S_{d}}{R}
$$

where $\lambda$ is the latent heat of vaporization of pure water (44.045 kJ mol-1 at $25^{\circ} \mathrm{C}$ ), and $\Delta S_{d}$ is the differential entropy of sorption $\left(\mathrm{kJ} \mathrm{mol}^{-1} \mathrm{~K}^{-1}\right)$.

From the intercept of the plot of $\ln \left(a_{w}\right)$ versus $1 / T$ at specified moisture levels of equation 5 , the differential entropy was evaluated.

\section{ENTHALPY-ENTROPY COMPENSATION THEORY}

A linear relationship between the isosteric heat of sorption (differential enthalpy) and differential entropy established the enthalpy-entropy theory (McMinn and Magee, 2003; Arslan and Toğrul, 2006):

$$
Q_{s t}=T_{\beta} \Delta S_{d}+\alpha
$$

where $Q_{s t}$ is the isosteric heat of sorption $\left(\mathrm{kJ} \mathrm{mol}^{-1}\right), T \beta$ is the isokinetic temperature $(\mathrm{K})$, and $\alpha$ is the constant $\left(\mathrm{kJ} \mathrm{mol}^{-1}\right)$.

The isokinetic temperature $\left(T_{\beta}\right)$ is a characteristic property of the material surface (Aguerre et al., 1986), and it represents the slope of the enthalpy-entropy linear relationship (eq. 6). Linear regression of $Q_{s t}$ with $\Delta S_{d}$ evaluated $T_{\beta}$ along with the constant $\alpha$. A statistical test proposed by Krug et al. (1976) verified the enthalpy-entropy compensation theory by defining the harmonic mean temperature $\left(T_{h m}\right)$ as:

$$
T_{h m}=\frac{n}{\sum_{1}^{n}(1 / T)}
$$

where $T_{h m}$ is the harmonic mean temperature $(\mathrm{K})$, and $n$ is the number of temperature levels.

Linear enthalpy-entropy compensation theory applies only when $T_{\beta} \neq T_{h m}$; the process is enthalpy driven if $T_{\beta}>T_{h m}$ and entropy driven if $T_{\beta}<T_{h m}$ (Leffer and Grunwald, 1963). Equation 7 shows that $T_{h m}$ is a function of temperature levels (T) selected for the experiment and is independent of the material considered. Analyses were conducted with $\alpha=0$ to evaluate the effect of temperature on the sorption behavior by introducing a temperature correction factor (Aguerre et al., 1986) as:

$$
-\ln \left(a_{w}\right)=\frac{Q_{s t}}{R\left(1 / T-1 / T_{\beta}\right)^{-1}}
$$

Although various relationships correlating equilibrium moisture content, water activity, and temperature were reported (Iglesias and Chirife, 1976b), Aguerre et al. (1986) proposed an exponential function for temperature dependence of sorption equilibrium of the form:

$$
\frac{Q_{s t}}{R}=\ln \left(a_{w}\right)\left(\frac{1}{T_{\beta}}-\frac{1}{T}\right)^{-1}=K_{1} K_{2}^{M}
$$

where $\left(1 / T_{\beta}-1 / T\right)^{-1}$ is the temperature correction factor $(\mathrm{K})$ of the isotherm, and $K_{1}(\mathrm{~K})$ and $K_{2}$ are constants.

Logarithmic transformation linearized equation 8. From the plot of $M$ versus $\ln \left[\ln \left(a_{w}\right)\left(1 / T_{\beta}-1 / T\right)^{-1}\right]$, constants $K_{1}$ and $K_{2}$ were obtained using exponential transformation from the intercept and slope of the curve, respectively.

\section{Spreading Pressure}

Spreading pressure was evaluated based on the analytical procedure described by Iglesias et al. (1976) and Fasina et al. (1999). Spreading pressure is given by the following equation:

$$
\pi=\frac{K T}{A_{m}} \int_{0}^{a_{w}} \frac{M}{M_{m} a_{w}}
$$

where $\pi$ is the spreading pressure $\left(\mathrm{J} \mathrm{m}^{-2}\right), K$ is the Boltzman constant $\left(1.380 \times 10^{-23} \mathrm{~J} \mathrm{~K}^{-1}\right)$, and $A_{m}$ is the surface area of a water molecule $\left(1.06 \times 10^{-19} \mathrm{~m}^{2}\right)$.

This integral becomes indeterminate at $a_{w}=0.0$. Therefore, spreading pressure was evaluated by dividing the total limit ( 0.0 to $a_{w}$ ) into a very small interval of 0.0 to 0.05 and the remaining 0.05 to $a_{w}$. The integral in the first infinitesimal $a_{w}$ range (0.0 to 0.05 ) was evaluated assuming a linear relationship (Henry's law) between $M$ and $a_{w}$ with usual notations (Fasina et al., 1999) as:

$$
\pi=\frac{K T M}{A_{m} M_{m}}
$$

The integral in the second $a_{w}$ range ( 0.05 to $\left.a_{w}\right)$ was evaluated after fitting isotherm data $\left(M, a_{w}\right)$ to the following Halsey equation:

$$
M=\left(\frac{-a}{\ln \left(a_{w}\right)}\right)^{1 / r}
$$

where a and $r$ are the Halsey isotherm model constants.

The spreading pressure obtained by integrating the Halsey model (eq. 11) in the second interval of 0.05 to aw (Iglesias et al., 1976) was:

$$
\pi=\frac{K T}{A_{m}} a^{\frac{1}{r}}\left[\frac{1}{\left(\frac{1}{r}-1\right)\left[-\ln \left(a_{w}\right)\right]^{\frac{1}{r}-1}}\right]_{0.05}^{a_{w}}
$$

Adding the results of the two selected aw intervals (eqs. 10 and 12) produced the spreading pressures at any studied temperature and water activity combination.

\section{NET INTEGRAL ENTHALPY}

Net integral enthalpy is analogous to isosteric heat of sorption (eq. 4). The net integral enthalpy based on the Gibbs equation (Hill and Rizvi, 1982) evaluated at constant spreading pressure is expressed with usual notations as:

$$
\left.\frac{\partial\left[\ln \left(a_{w}\right)\right]}{\partial[1 / T]}\right|_{\pi} \approx-\frac{Q_{i n}}{R}
$$

where $Q_{\text {in }}$ is the integral enthalpy $\left(\mathrm{kJ} \mathrm{mol}^{-1}\right)$.

The slope from the plot of $\ln \left(a_{w}\right)$ versus $1 / T$ at constant $\pi$ produced the net integral enthalpy. For plotting, $a_{w}$ values at 
selected levels of $\pi$ were obtained through interpolation at various temperatures.

\section{NET INTEGRAL ENTROPY}

Net integral entropy for a thermodynamic system was based on the following relationship (Benado and Rizvi, 1985):

$$
S_{i n}=\frac{-Q_{i n}}{T}-R \ln \left(a_{w}^{*}\right)
$$

where $S_{\text {in }}$ is the net integral entropy $\left(\mathrm{kJ} \mathrm{mol}^{-1} \mathrm{~K}^{-1}\right)$, and $a_{w}{ }^{*}$ is the geometric mean water activity at constant $\pi$. The temperature term $T$ of equation 14 was interpolated linearly for $a_{w}{ }^{*}$ from the $T$ and $a_{w}$ data for a given $\pi$.

\section{Results AND Discussion \\ BET Monolayer Moisture Contents}

Standard BET and modified BET monolayer moisture contents of corn stover fractions decreased with increase in temperature (fig. 3). In general, leaf and stalk skin monolayer moisture contents had similar distribution with temperature, and their monolayer moisture values were distinctly greater than that of stalk pith. Mean and standard deviation values of standard BET monolayer moisture contents at temperatures ranging from $10^{\circ} \mathrm{C}$ to $40^{\circ} \mathrm{C}$ were estimated as $4.87 \%$ $\pm 0.87 \%, 4.89 \% \pm 0.71 \%$, and $3.78 \% \pm 1.41 \%$ d.b. for leaf, stalk skin, and stalk pith, respectively. The modified BET monolayer moisture contents closely matched, with corresponding values of $4.84 \% \pm 0.95 \%, 4.85 \% \pm 0.74 \%$, and $3.75 \% \pm 1.21 \%$ d.b., whereas the initial moisture contents of these fractions were determined as $8.11 \%$, $12.19 \%$, and $6.09 \%$ d.b., respectively. Negative coefficients of temperatures of the modified BET equation (fig. 3) indicate reduction in monolayer moisture with temperature increase. Stalk pith produced the greatest reduction of monolayer moisture with increasing temperature, and stalk skin produced the smallest reduction. Iglesias and Chirife (1976a) and Rahman and Labuza (1999) reported that monolayer values decreased significantly with increasing temperature for food and its components. This reduction in monolayer moisture content was attributed to the reduction in the number of active sites due to physical and chemical changes induced by the temperature increase (Aviara et al., 2004).

Standard BET plots produced negative intercepts and thereby negative values of $C$ at some conditions of leaf and stalk pith. As the negative $C$ values produced unrealistic $a_{w m}$ values (eq. 3) corresponding to the monolayer moisture contents, an arbitrary small value of 0.0001 for the intercept was assumed, and BET plot slopes and $C$ values were recalculated in such cases. For the three materials studied, the value of $C$ varied widely, from 12 to 4316 , which gave corresponding water activity values corresponding to monolayer moisture contents in the range of $0.225<a_{w m}<$ 0.013 . Nonlinear regression fit of the modified BET equation gave negative $C$ only for leaf; therefore, a mean $C$ value of 1309.64, obtained from the standard BET procedure among all the temperatures, was utilized and other model constants were recalculated. The $C$ values did not affect the performance of the BET and modified BET models. A loglog plot of $a_{w m}$ with $C$ gave a linearly decreasing variation, and the variation can be represented by the power equation $a_{w m}=0.7527 C^{-4856}\left(\mathrm{R}^{2}=0.9988\right)$. Based on equation 3 , the maximum value $a_{w m}$ takes is 0.5 when $C$ approaches the minimum value of 1.0. Although fractional values for $C$ $(0.0<C<1.0)$ in equation 3 gave positive $a_{w m}$ values $(>0.5)$, these high water activity values were not realistic for the monolayer moisture contents observed. The determined $C$ values for leaf, stalk skin, and stalk pith were 1309.64, 14.58 , and 95.53 , respectively, and the corresponding $a_{w m}$ values were $0.0269,0.2075$, and 0.0928 .

\section{Net Isosteric HeAt OF SORPTION ANd Differential ENTROPY}

Net isosteric heat of sorption of corn stover fractions decreased exponentially with increase in moisture content (fig. 4). Net isosteric heat of sorption decreased very gradually or can be considered stabilized, when the moisture in the material was greater than $20 \%$ d.b.

Increased heat of sorption values (in addition to latent heat of vaporization) at reduced moisture levels indicated high binding energy for removal of water. Increasing moisture content decreased the heat of sorption and the values tended to approach that of pure water at about $15 \%$ d.b., indicating water existence in free form (Aviara and Ajibola, 2002; Kaya

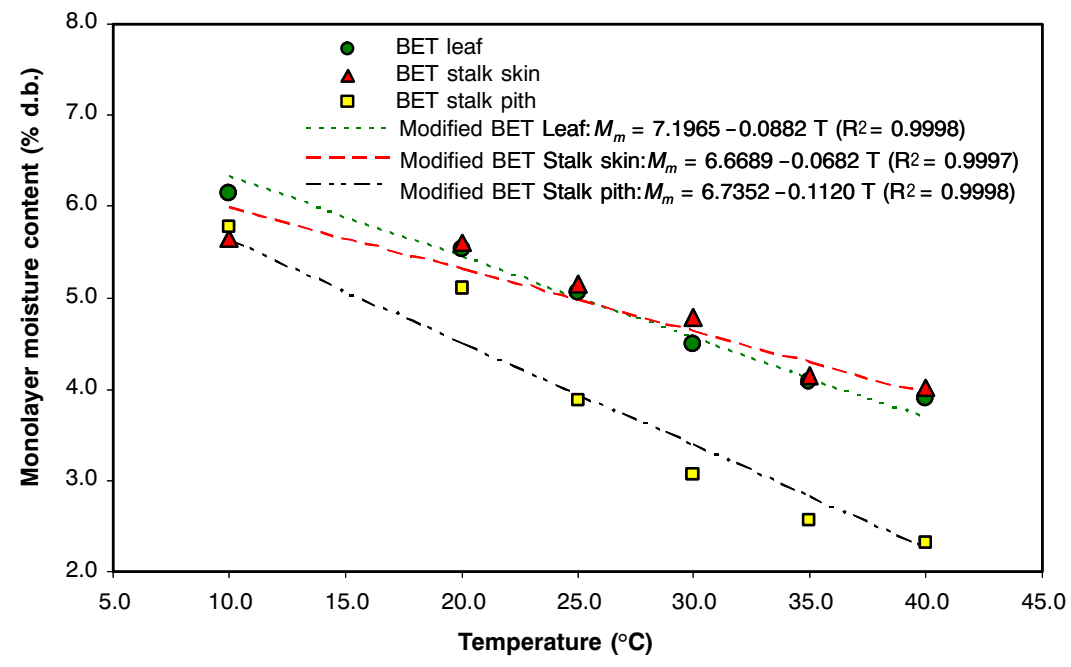

Figure 3. Monolayer moisture content of corn stover fractions at different temperatures by standard BET and modified BET equations. 


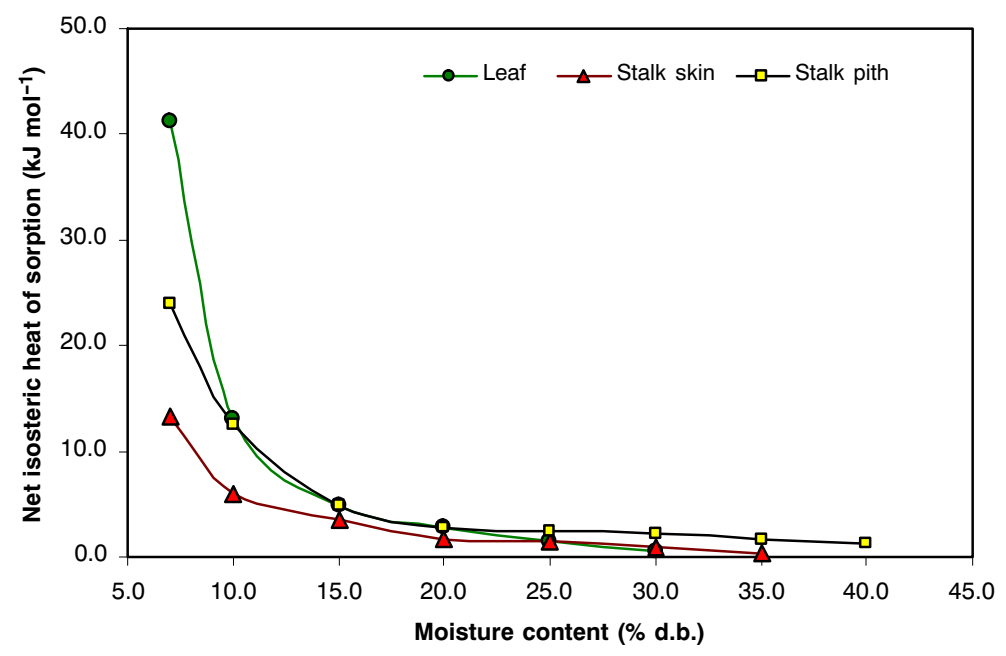

Figure 4. Net isosteric heat of sorption of corn stover fractions with moisture content.

and Kahyaoglu, 2005). At low moisture levels (<10\% d.b.), leaf had the greatest heat of sorption value, followed by stalk pith and stalk skin. At increased moisture levels, stalk pith had the maximum value, followed by stalk skin and leaf. Mean net isosteric heat of sorption values for leaf, stalk skin, and stalk pith were $4.60 \pm 5.05,2.32 \pm 2.11$, and 4.00 $\pm 3.94 \mathrm{~kJ} \mathrm{~mol}^{-1}$, respectively, in the moisture range of $10 \%$ to $40 \%$ d.b. This shows that reduced energy is required to extract moisture from stalk skin, followed by leaf and stalk pith. Typical heat of sorption values reported for some agricultural products are: corn grain $\left(3\right.$ to $\left.65 \mathrm{~kJ} \mathrm{~mol}^{-1}\right)$ and sorghum (1 to $35 \mathrm{~kJ} \mathrm{~mol}^{-1}$ ) (Cenkowski et al. 1992), pineapple (5 to $30 \mathrm{~kJ} \mathrm{~mol}^{-1}$ ) (Hossain et al., 2001), quinoa seeds (4 to $47 \mathrm{~kJ} \mathrm{~mol}^{-1}$ ) (Tolaba et al., 2004), and tea (44 to $60 \mathrm{~kJ} \mathrm{~mol}^{-1}$ ) (Arslan and Toğrul, 2006).

Differential entropy (fig. 5) followed similar trends as net isosteric heat of sorption (fig. 4) of initial exponential decrease and stabilization with increase in moisture. In the moisture range of $10 \%$ to $40 \%$ d.b, the mean differential entropy values of leaf, stalk skin, and stalk pith were $0.0133 \pm 0.0149,0.0062$ \pm 0.0052 , and $0.0118 \pm 0.0118 \mathrm{~kJ} \mathrm{~mol}^{-1} \mathrm{~K}^{-1}$, respectively. Large values of heat of sorption and differential entropy associated with low moisture values represent bound moisture.

\section{ENTHALPY-ENTROPY COMPENSATION THEORY}

Isokinetic temperatures $\left(T_{\beta}\right)$ of leaf, stalk skin, and stalk pith were $324.31 \mathrm{~K}, 372.68 \mathrm{~K}$, and $327.74 \mathrm{~K}$, respectively, and the harmonic mean temperature $\left(T_{h m}\right)$ was $299.54 \mathrm{~K}$. Inequality of these temperature values $\left(T_{\beta}>T_{h m}\right)$ confirmed the enthalpy-entropy compensation theory (Leffer and Grunwald, 1963). Because $T_{\beta}>T_{h m}$, the moisture sorption process was determined as enthalpy driven. Differential enthalpy (isosteric heat of sorption) varied linearly with differential entropy (fig. 6), and the linear model fitted well with all corn stover fractions $\left(\mathrm{R}^{2} \geq 0.9978\right)$. Values of constant $\alpha$ of the linear differential enthalpy-entropy fit (eq. 6) were determined as $44.30,44.02,44.15 \mathrm{~kJ} \mathrm{~mol}^{-1}$ for leaf, stalk skin, and stalk pith, respectively, and these values were practically the same for all materials tested.

Values of temperature dependence of sorption moisture equilibrium function constant $K_{1}$ (eq. 8) of leaf were much greater than that of stalk pith and stalk skin, whereas $K_{2}$ values were relatively constant, although stalk pith recorded slightly increased values (table 1). Previously reported sorption-based $K_{1}$ and $K_{2}$ values were $3695 \mathrm{~K}$ and 0.882 for potato (McMinn and Magee, 2003), and $8957 \mathrm{~K}$ and 0.842 for rough rice (Aguerre et al., 1986), respectively. Some of these

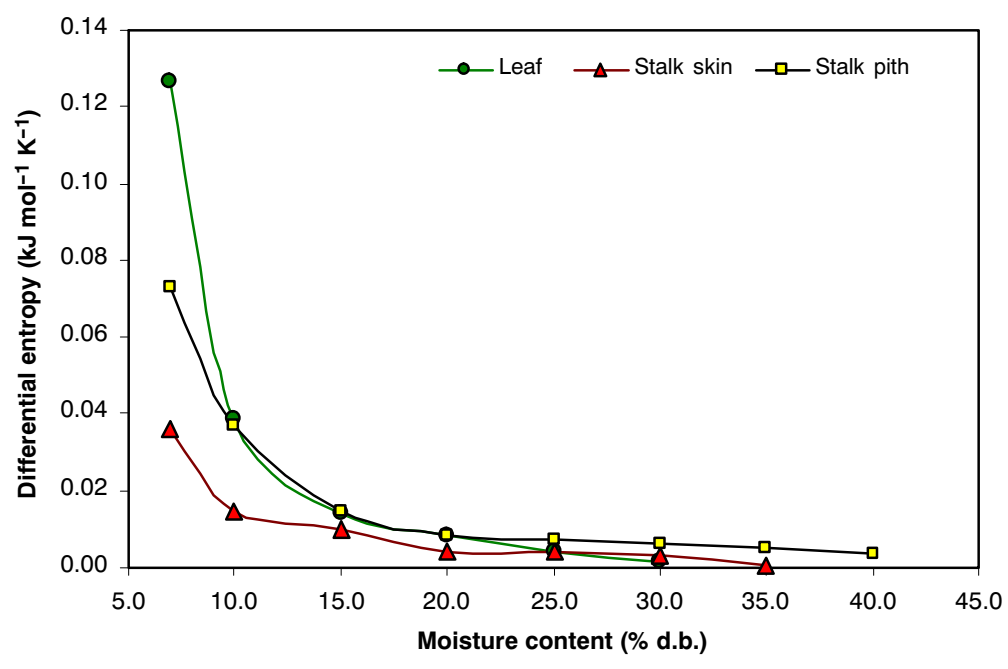

Figure 5. Differential entropy of corn stover fractions with moisture content. 


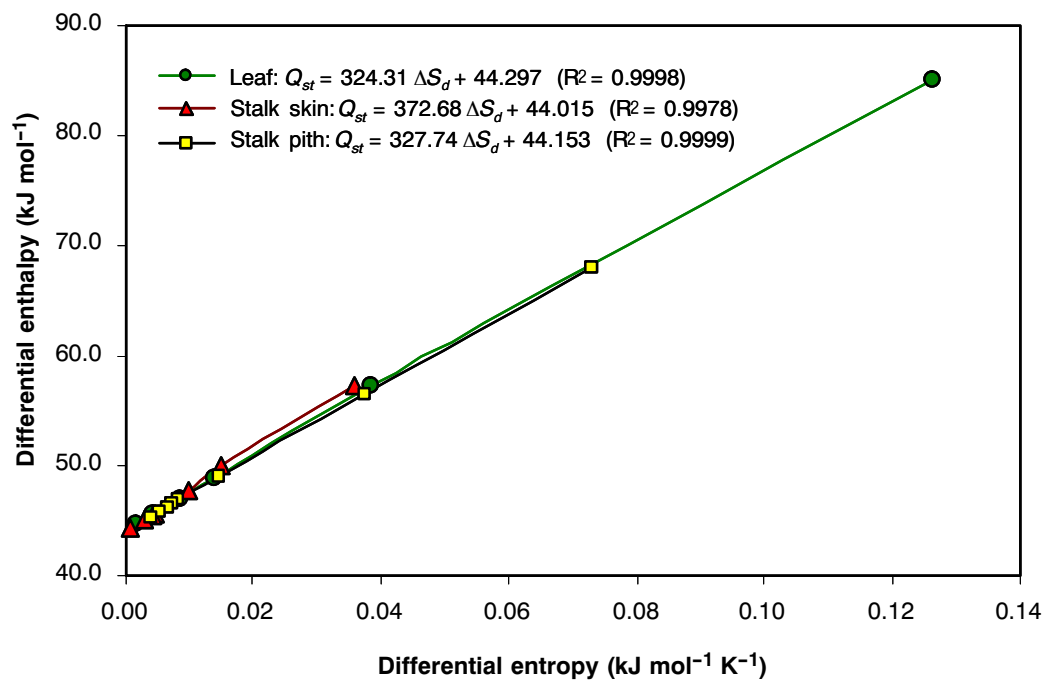

Figure 6. Linear relationship of differential enthalpy and differential entropy of corn stover fractions.

Table 1. Enthalpy-entropy compensation theory constants.

\begin{tabular}{cccccccc}
\hline & \multicolumn{3}{c}{$K_{1}(\mathrm{~K})$} & & \multicolumn{3}{c}{$K_{2}$} \\
\cline { 2 - 4 } \cline { 7 - 8 } $\begin{array}{c}\text { Temperature } \\
\left({ }^{\circ} \mathrm{C}\right)\end{array}$ & Leaf & $\begin{array}{c}\text { Stalk } \\
\text { skin }\end{array}$ & $\begin{array}{c}\text { Stalk } \\
\text { pith }\end{array}$ & & Leaf & $\begin{array}{c}\text { Stalk } \\
\text { skin }\end{array}$ & $\begin{array}{c}\text { Stalk } \\
\text { pith }\end{array}$ \\
\hline 10 & 12110 & 2759 & 3623 & & 0.855 & 0.886 & 0.919 \\
20 & 8045 & 3068 & 2872 & & 0.884 & 0.881 & 0.935 \\
25 & 8525 & 3299 & 3022 & & 0.883 & 0.880 & 0.932 \\
30 & 7567 & 3079 & 4081 & & 0.890 & 0.877 & 0.917 \\
35 & 10808 & 3515 & 3924 & & 0.881 & 0.870 & 0.922 \\
40 & 13869 & 4895 & 4339 & & 0.884 & 0.848 & 0.928 \\
\hline
\end{tabular}

reported $K_{1}$ and $K_{2}$ values were comparable to the constants of corn stover fractions of the present study (table 1 ).

\section{Spreading Pressure}

The Halsey isotherm equation modeled the sorption isotherm data of corn stover fractions adequately $\left(\mathrm{R}^{2}>\right.$ 0.983). Leaf generally had the highest spreading pressure, followed by stalk skin and stalk pith at temperatures $<35^{\circ} \mathrm{C}$. Spreading pressures mean and standard deviation values for leaf, stalk skin, and stalk pith were calculated as $0.74 \pm 0.33$,
$0.71 \pm 0.31$, and $0.65 \pm 0.38 \mathrm{~J} \mathrm{~m}^{-2}$, respectively. Spreading pressure of corn stover fractions increased with water activity, and the curves had shapes of type II moisture isotherms, which are evident from the typical plots at $10^{\circ} \mathrm{C}$ and $40^{\circ} \mathrm{C}$ (fig. 7). An increase in temperature reduced the spreading pressure of all corn stover fractions. The values of spreading pressures, water activities, and variations with temperature of corn stover fractions were similar to those reported by Kaya and Kahyaoglu (2005) for pestil (grape leather).

\section{Net InTEgral ENTHALPY AND Net INTEGRAL ENTROPY}

Net integral enthalpy increased initially as moisture content increased to a level of about $10 \%$ to $12 \%$ d.b. and then decreased with further increase in moisture for all the corn stover fractions (fig. 8). Similar variations were reported for net integral enthalpy of melon seed and cassava (Aviara and Ajibola, 2002), potato (McMinn and Magee, 2003), and pestil (Kaya and Kahyaoglu, 2005). The initial increase in enthalpy at low moisture contents was due to water absorbed on the most accessible sites on the solid exterior surface.

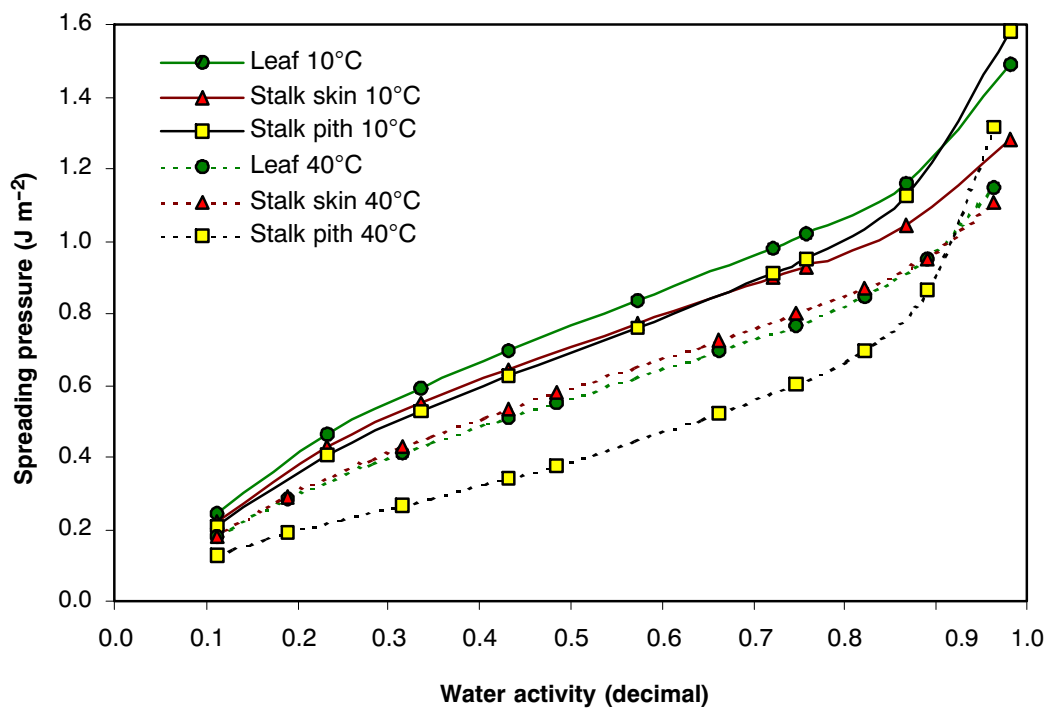

Figure 7. Typical plots of spreading pressure variation of corn stover fractions with water activity at $10^{\circ} \mathrm{C}$ and $40^{\circ} \mathrm{C}$. 


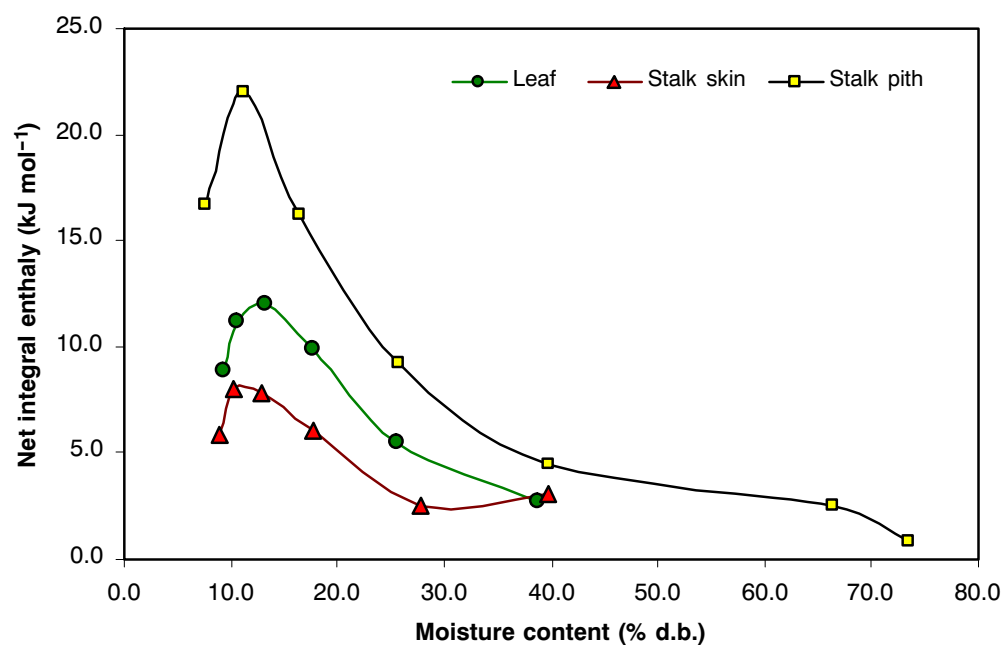

Figure 8. Net integral enthalpy variations of corn stover fractions with moisture content.

Further increase in moisture made the material swell and opened up new high-energy sites for water to get bound to, which increased the net integral enthalpy. The increase at low moisture contents continued until binding sites were covered. The net integral enthalpy after reaching a maximum value declined with further increase in moisture levels as less favorable sites were covered and multiple layers of sorbed water formed (Aviara and Ajibola, 2002; McMinn and Magee, 2003; Kaya and Kahyaoglu, 2005). In the present study, stalk pith registered the largest net integral enthalpy value, followed by leaf and stalk skin at a given moisture content, and the corresponding mean values were $10.30 \pm 7.67,8.34 \pm 3.58$, and $5.58 \pm 2.31 \mathrm{~kJ} \mathrm{~mol}^{-1}$.

Variation of net integral entropy (fig. 9) was found to be a mirror image of the net enthalpy variation about moisture content (fig. 8). The net integral entropy variation decreased initially and then increased with an increase in moisture content. The decrease of entropy in the low moisture range was attributed to increased restriction in the movement (loss of rotational freedom or degree of randomness) of water molecules, as the readily available sites became saturated and the strongest binding sites were utilized. The minimum entropy occurred when the sorbed water became completely localized as the first layer was covered. Subsequent increase of entropy indicated the availability of more freely held moisture and the formation of multi-layers of moisture (Aviara and Ajibola, 2002; McMinn and Magee, 2003; Kaya and Kahyaoglu, 2005). Mean values of net integral entropy, from the present study, were $-0.0324 \pm 0.0238$, $-0.0248 \pm 0.0106$, and $-0.0158 \pm 0.0064 \mathrm{~kJ} \mathrm{~mol}^{-1} \mathrm{~K}^{-1}$ for stalk pith, leaf, and stalk skin, respectively. At high moisture levels, net integral entropy approached the net integral entropy value of free liquid water $\left(0.0 \mathrm{~kJ} \mathrm{~mol}^{-1} \mathrm{~K}^{-1}\right)$.

\section{SUMMARY}

Moisture sorption isotherm data of leaf, stalk skin, and stalk pith fractions of corn stover obtained from the static gravimetric method, in the temperature range of $10^{\circ} \mathrm{C}$ to $40^{\circ} \mathrm{C}$, were used in determining thermodynamic properties. Standard BET and modified BET monolayer moisture contents of the corn stover fractions matched closely, and these values decreased with increase in temperature. The mean standard BET monolayer moisture contents were $4.87 \% \pm 0.87 \%$ d.b. for leaf, $4.89 \% \pm 0.71 \%$ d.b. for stalk skin, and $3.78 \% \pm 1.41 \%$ d.b. for stalk pith. The water activity associated with monolayer moisture contents varied

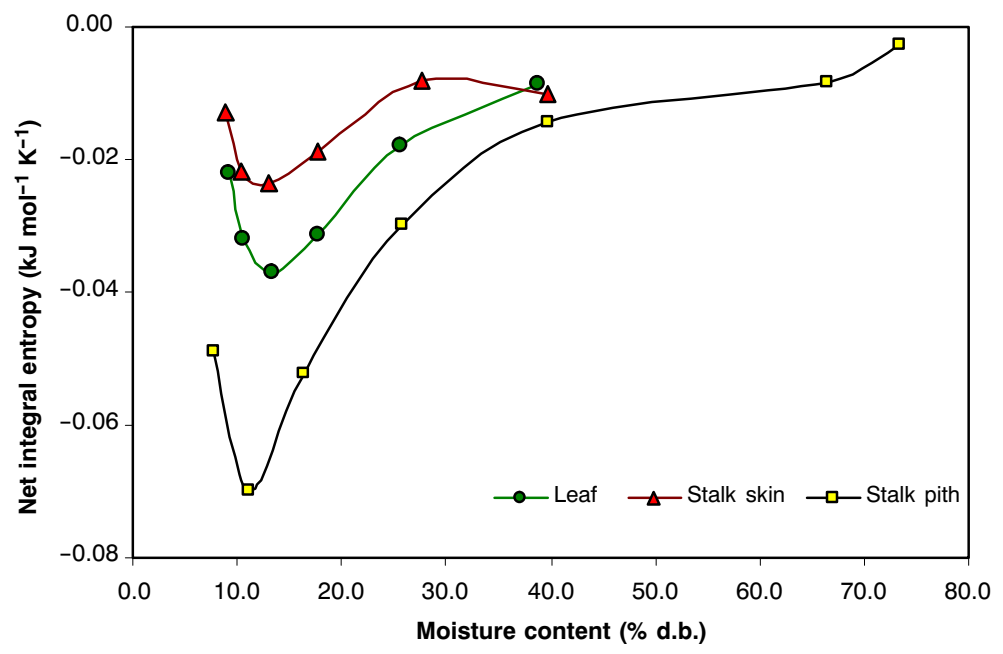

Figure 9. Net integral entropy variations of corn stover fractions with moisture content. 
widely from 0.013 to 0.225 . Net isosteric heat of sorption and differential entropy of corn stover fractions decreased exponentially with moisture increase and approached the latent heat of vaporization of pure water. In the moisture range of $10 \%$ to $40 \%$ d.b., the mean net isosteric heat of sorption for leaf, stalk skin, and stalk pith was $4.60 \pm 5.05$, $2.32 \pm 2.11$, and $4.00 \pm 3.94 \mathrm{~kJ} \mathrm{~mol}^{-1}$ and mean differential entropy values were $0.0133 \pm 0.0149,0.0062 \pm 0.0052$, and $0.0118 \pm 0.0118 \mathrm{~kJ} \mathrm{~mol}^{-1} \mathrm{~K}^{-1}$, respectively.

Isokinetic temperatures $(>324 \mathrm{~K})$ were greater than harmonic mean temperature $(299.5 \mathrm{~K})$ of the corn stover fractions, and this inequality confirmed the enthalpy-entropy compensation theory. The moisture sorption process was predominantly enthalpy driven. Spreading pressures, obtained by modeling the sorption isotherm data of corn stover fractions using the Halsey isotherm equation $\left(\mathrm{R}^{2}>0.983\right)$ were the greatest for leaf, followed by stalk skin and stalk pith at temperatures $<35^{\circ} \mathrm{C}$, with corresponding overall mean values of $0.74 \pm 0.33,0.71 \pm 0.31$, and $0.65 \pm 0.38 \mathrm{~J} \mathrm{~m}^{-2}$. Spreading pressures increased with increasing water activity, and decreased with increasing temperature. Net integral enthalpy increased with moisture content to a maximum and decreased thereafter, and the mean values were $10.30 \pm 7.67$, $8.34 \pm 3.58$, and $5.58 \pm 2.31 \mathrm{~kJ} \mathrm{~mol}^{-1}$ for stalk pith, leaf, and stalk skin, respectively. Net integral entropy decreased with moisture increase to a minimum and increased thereafter, and displayed a reverse trend with net integral enthalpy. Mean values of net integral entropy for stalk pith, leaf, and stalk skin were $-0.0324 \pm 0.0238,-0.0248 \pm 0.0106$, and -0.0158 $\pm 0.0064 \mathrm{~kJ} \mathrm{~mol}^{-1} \mathrm{~K}^{-1}$, respectively.

\section{ACKNOWLEDGEMENTS}

The financial support by the Bioenergy Feedstock Development Program of the Oak Ridge National Laboratory (Subcontract No. 34000008088) and the assistance extended by Dr. Mark Radosevich is acknowledged.

\section{REFERENCES}

Aguerre, R. J., C. Suarez, and P. E. Viollaz. 1986. Enthalpy-entropy compensation in sorption phenomena: Application to the prediction of the effect of temperature on food isotherms. $J$. Food Sci. 51(6): 1547-1549.

Arslan, N., and H. Toğrul. 2006. The fitting of various models to water sorption isotherms of tea stored in a chamber under controlled temperature and humidity. J. Stored Prod. Res. 42(2): 112-135.

ASAE Standards. 2003. S358.2: Moisture measurement - forages. St. Joseph, Mich.: ASAE.

Aviara, N. A., and O. O. Ajibola. 2002. Thermodynamics of moisture sorption in melon seed and cassava. J. Food Eng. 55(2): 107-113.

Aviara, N. A., O. O. Ajibola, and S. A. Oni. 2004. Sorption equilibrium and thermodynamic characteristics of soya bean. Biosystems Eng. 87(2): 179-190.

Bell, L. N., and T. P. Labuza. 2000. Moisture Sorption: Practical Aspects of Isotherm Measurement and Use. St. Paul, Minn.: American Association of Cereal Chemists.

Benado, A. L., and S. S. H. Rizvi. 1985. Thermodynamic properties of water on rice as calculated from the reversible and irreversible isotherms. J. Food Sci. 50(2): 101-105.

Brunauer, S., P. H. Emmett, and E. Teller. 1938. Adsorption of gases in multimolecular layers. J. American Chem. Soc. 60(2): 309-319.
Cenkowski, S., D. S. Jayas, and D. Hao. 1992. Latent heat of vaporization for selected foods and crops. Canadian Agric. Eng. 34(3): 281-286.

Fasina, O. O., O. O. Ajibola, and R. T. Tyler. 1999. Thermodynamics of moisture sorption in winged bean seed and gari. J. Food Proc. Eng. 22(6): 405-418.

Hill, P. E., and S. S. H. Rizvi. 1982. Thermodynamic parameters and storage stability of drum dried peanut flakes. Lebensm.-Wiss. Technol. 15(2): 185-190.

Hoskinson, R. L., D. L. Karlen, S. J. Birrell, C. W. Radtke, and W. W. Wilhelm. 2007. Engineering, nutrient removal, and feedstock conversion evaluations. Biomass Bioenergy 31(2-3): 126-136.

Hossain, M. D., B. K. Bala, M. A. Hossain, and M. R. A. Mondol. 2001. Sorption isotherms and heat of sorption of pineapple. $J$. Food Eng. 48(2): 103-107.

Igathinathane, C., A. R. Womac, S. Sokhansanj, and L. O. Pordesimo. 2005a. Thermodynamic properties and mold appearance on selected corn stover components. ASABE Paper No. 056047. St. Joseph, Mich.: ASABE.

Igathinathane, C., A. R. Womac, S. Sokhansanj, and L. O. Pordesimo. 2005b. Sorption equilibrium moisture characteristics of selected corn stover components. Trans. ASAE 48(4): 1449-1460.

Igathinathane, C., A. R. Womac, S. Sokhansanj, and L. O. Pordesimo. 2006. Mass and moisture distribution in aboveground components of standing corn plants. Trans. ASABE 49(1): 97-106.

Iglesias, H. A., and J. Chirife. 1976a. B.E.T. monolayer values in dehydrated foods and food components. Lebensm.-Wiss. Technol. 9(2): 107-113.

Iglesias, H. A., and J. Chirife. 1976b. Isosteric heats of water vapor sorption on dehydrated foods: Part I. Analysis of the differential heat curves. Lebensm.-Wiss. Technol. 9(2): 116-122.

Iglesias, H. A., J. Chirife, and P. Viollaz. 1976. Thermodynamics of water vapour sorption by sugar beet root. J. Food Tech. 11(1): 91-101.

Kaya, S., and T. Kahyaoglu. 2005. Thermodynamic properties and sorption equilibrium of pestil (grape leather). J. Food Eng. 71(2): 200-207.

Kim, S., and B. E. Dale. 2004. Global potential bioethanol production from wasted crops and crop residues. Biomass Bioenergy 26(4): 361-375.

Krug, R. R., W. G. Hunter, and R. A. Grieger. 1976. Enthalpy-entropy compensation 2-separation of the chemical from the statistical effect. J. Phys. Chem. 80(21): 2341-2346.

Leffer, J. E., and E. Grunwald. 1963. Rates and Equilibria of Organic Reactions. New York, N.Y.: Wiley.

Madamba, P. S., R. H. Driscoll, and K. A. Buckle. 1996. Enthalpy-entropy compensation models for sorption and browning of garlic. J. Food Eng. 28(2): 109-119.

Mazza, G., and M. Le Maguer. 1978. Water sorption properties of yellow globe onion. Canadian Inst. Food Sci. Tech. 11(4): 189-193.

McMinn, W. A. M., and T. R. A. Magee. 2003. Thermodynamic properties of moisture sorption of potato. J. Food Eng. 60(2): $157-165$.

Menkov, N. D. 2000. Moisture sorption isotherms of vetch seeds at four temperatures. J. Agric. Eng. Res. 76(4): 373-380.

Rahman, M. S., and T. P. Labuza. 1999. Water activity and food preservation. In Handbook of Food Preservation, 1-86. M. S. Rahman, ed. New York, N.Y.: Marcel Dekker.

Rizvi, S. S. H. 1986. Thermodynamic properties of food in dehydration. In Engineering Properties of Foods, 133-214. M. A. Rao, and S. S. H. Rizvi, eds. New York, N.Y.: Marcel Dekker.

Rizvi, S. S. H., and A. L. Benado. 1984. Thermodynamic analysis of drying foods. Drying Tech. 2(4): 471-502.

SAS. 2002. SAS version 9 online help and documentation. Cary, N.C.: SAS Institute, Inc. 
Smith, J. M., H. C. Van Ness, and M. M. Abbott. 2001. Introduction to Chemical Engineering Thermodynamics. Boston, Mass.: McGraw-Hill.

Tolaba, M. P., M. Peltzer, N. Enriquez, and M. L. Pollio. 2004. Grain sorption equilibria of quinoa grains. J. Food Eng. 61(3): 365-371.

USDOE. 2003. Biomass program: Multiyear technical plan. Available at: www.biomass.govtools.us/pdfs/ MYTP\%20FY\%202002\%20v13.pdf. Accessed 3 May 2007.

\section{NOMENCLATURE}

$A, B, C$ model constants of modified BET monolayer moisture content

$a, r \quad$ Halsey isotherm models constants

$a_{w} \quad$ water activity (decimal)

$a_{w m} \quad$ water activity corresponding to the monolayer moisture content (decimal)

$a_{w}{ }^{*} \quad$ geometric mean water activity at constant spreading pressure (decimal)

$A_{m} \quad$ surface area of a water molecule $\left(1.06 \times 10^{-19} \mathrm{~m}^{2}\right)$

$K \quad$ Boltzman constant $\left(1.380 \times 10^{-23} \mathrm{~J} \mathrm{~K}^{-1}\right)$
$K_{1}, K_{2}$ first constant (K) and second constant (dimensionless) of temperature dependence of sorption equilibrium equation 8

$M \quad$ equilibrium moisture content (\% d.b.)

$M_{m} \quad$ monolayer moisture content (\% d.b.)

$n \quad$ number of temperature levels considered

$Q_{i n} \quad$ net integral enthalpy $\left(\mathrm{kJ} \mathrm{mol}^{-1}\right)$

$Q_{s t} \quad$ isosteric heat of sorption $\left(\mathrm{kJ} \mathrm{mol}^{-1}\right)$

$q_{s t} \quad$ net isosteric heat of sorption $\left(\mathrm{kJ} \mathrm{mol}^{-1}\right)$

$R \quad$ universal gas constant $(8.31434 \times$ $10^{-3} \mathrm{~kJ} \mathrm{~mol}^{-1} \mathrm{~K}^{-1}$ )

$\mathrm{R}^{2} \quad$ coefficient of determination

$\Delta S_{d} \quad$ differential entropy of sorption $\left(\mathrm{kJ} \mathrm{mol}^{-1} \mathrm{~K}^{-1}\right)$

$S_{\text {in }} \quad$ net integral entropy $\left(\mathrm{kJ} \mathrm{mol}^{-1} \mathrm{~K}^{-1}\right)$

$T$ temperature (K)

$T_{c} \quad$ temperature $\left({ }^{\circ} \mathrm{C}\right)$

$T_{\beta} \quad$ isokinetic temperature (K)

$T_{h m} \quad$ harmonic mean temperature (K)

$\alpha \quad$ constant of equation $6\left(\mathrm{~kJ} \mathrm{~mol}^{-1}\right)$

$\lambda$ latent heat of vaporization of pure water $\left(44.045 \mathrm{~kJ} \mathrm{~mol}^{-1}\right.$ at $\left.25^{\circ} \mathrm{C}\right)$

$\pi \quad$ spreading pressure $\left(\mathrm{J} \mathrm{m}^{-2}\right)$ 